\title{
Yergin Panel Assessment on Energy R\&D: Good News for Materials Research
}

Why is a recent Department of Energy report by a special Task Force on Strategic Energy R\&D of interest to materials researchers? Answer: DOE, which commissioned the study of its energy $R \& D$ portfolio, provides nearly one-half of federal support for materials research in the United States. This includes one-third of federally supported fundamental materials research as well as operation of most of the nation's major materials research facilities such as synchrotrons and neutron sources. The majority of this support is provided through DOE's energy technology and basic energy sciences programs. The energy $R \& D$ mission is broad, and DOE materials research programs have an enormous impact on scientific and technological progress in the materials field. The research is performed in DOE laboratories, universities, and industry.

According to the nine-month study by industry and university experts, DOE should "examine mechanisms for maintaining a strong energy $R \& D$ program, while cutting total costs." The study, convened by Secretary of Energy Hazel R. $\mathrm{O}^{\prime}$ Leary, was chaired by Pulitzer Prize winning author and energy consultant Daniel Yergin. The panel concluded that DOE's energy R\&D contributions have been significant, contributing along with other federal and private investments to a higher standard of living. Many of these contributions have been in the form of new materials and materials technologies for a wide variety of energy production and end-use applications. The report also noted that DOE's energy programs could be made more efficient, lowering costs without reducing the direct research effort.

The report reviews recent changes in the R\&D landscape: the end of the Cold War, increasing competitive pressures in the private sector, realignments at research universities, and shifting priorities in federal spending away from $R \& D$. $R \& D$ investment is declining in the federal government and increasingly focused on the short term in industry. This foreshadows a looming R\&D crisis caused by widespread cutbacks and shortened time horizons at a time when science and technology are of growing importance to meeting global challenges.

Although energy is fundamental to the functioning of industrial society, federal support for energy R\&D has fallen significantly since the late 1970 s with the decline of large energy demonstration projects. During this period, Japanese investment in energy $R \& D$ has increased and is currently twice that of the United States. While a major oil shock is not anticipated, the world oil market is currently operating at $96 \%$ capacity and oil demand in Asia will exceed that of North America in less than five years. Overall, global energy demand will increase $40 \%$ in the next 15 years.

The report notes that energy R\&D now constitutes less than $15 \%$ of the DOE budget, which is dominated by environmental remediation and nuclear weapons programs. DOE's energy R\&D portfolio includes energy efficiency, renewable energy, fusion energy, coal, oil, natural gas, and nuclear fission. Basic energy sciences support basic research in areas of science (including materials science) important to energy and other missions of DOE and operate advanced scientific research facilities for the benefit of the nation. In FY 1995, DOE is investing approximately $\$ 2.4$ billion in energy R\&D, $\$ 1.7$ billion in energy technologies, and $\$ 700$ million in basic energy sciences. DOE's energy R\&D budget is about $0.5 \%$ of the nation's annual energy expenditures of $\$ 500$ billion.

The panel recommends that the appropriate role for the federal government in $\mathrm{R} \& D$ is to support activities which serve national interests not adequately addressed by market forces. Cost sharing with industry can be a useful mechanism to leverage resources, ensure relevance, and accelerate the $R \& D$ process and its impact. An emerging need for "concurrent" R\&D is bridging the traditional division between basic and applied research.

The report makes a number of recommendations, foremost that the federal government "continue to provide leadership, focus, and substantial financial support for energy R\&D to ensure that the national goals of U.S. energy security, economic strength, environmental quality, and national leadership in science and technology are effectively achieved."

The panel further recommends cost savings of $15 \%$ in energy $R \& D$ through administrative, compliance, and overhead cuts, without reducing funds going directly to scientists and engineers engaged in research. These cuts, which will require the cooperation of Congress, are consistent with efficiencies which should result from adopting private sector "best practices."

The report also recommends integrating the energy R\&D portfolio under a single person reporting to the Secretary of Energy and exploring innovative funding options such as a two-year funding cycle to improve continuity in $R \& D$ programs.

Overall, the report makes a credible case for the effectiveness of DOE's energy R\&D program. An annex to the report details 60 of DOE's most significant success stories, and an economic analysis of the Office of Industrial Technologies gives a net economic benefit of $\$ 500$ million in excess of appropriations over the past 15 years. The report argues that while prudent reductions in energy $R \& D$ are possible, particularly through needed efficiency improvements, the nation's science and technology base, a key driver for economic growth, must be maintained. This is good news for materials research, an essential underpinning component of energy $R \& D$.

"Energy R\&D: Shaping our Nation's Future in a Competitive World," is available on the World Wide Web: http:// www.doe.gov/.

JAMES B. ROBER'TO

James B. Roberto is director of the Solid State Division at Oak Ridge National Laboratory.

\section{Optical Society of America and Materials Research Society Seek Applicants for the 1996-1997 OSA/MRS CONGRESSIONAL SCIENCE AND ENGINEERING FELLOWSHIP PROGRAM}

Deadline: January 15, 1996

Term: One year

Qualifications: PhD degree or equivalent in a field relevant to optical and/or materials science and technology.

Stipend: Up to $\$ 40,000$

How to apply: For application details contact MRS at phone (412) 367-3003 or e-mail oare@mrs.org, or OSA at phone (202) 223-8130 or e-mail sreiss@osa.org. 